\title{
Variação da reflexão de diferentes ondas de uma região de cerrado da baixada Cuiabana sob diferentes coberturas do céu.
}

\author{
Different waves variation reflection of a savannah in Cuiabá region under different \\ covers of the sky.
}

\author{
Cristiano Rocha da Cunha* ${ }^{* 1}$, José de Souza Nogueira ${ }^{1}$, Osvaldo Borges Pinto Junior ${ }^{1}$, \\ Carlo Ralph de Musis ${ }^{1}$, Flair José Carrilho Sobrinho ${ }^{1}$
}

${ }^{1}$ Programa de Pós Graduação em Física Ambiental, Universidade Federal do Mato Grosso, Cuiabá, Brasil.

\begin{abstract}
Resumo
A energia disponível para os processos físicos, químicos e biológicos no planeta não é integralmente aquela que o Sol disponibiliza durante o dia, parte desta energia é devolvida ao espaço através da reflexão, inicialmente pela atmosfera, juntamente com as nuvens e, na sequencia, a cobertura da superfície. Este trabalho estudou a influência da cobertura celeste nos coeficientes de reflexão das radiações global, fotossinteticamente ativa (PAR) e infravermelho (IV), durante dois períodos, seco e chuvoso, de uma região de Cerrado stricto sensu da baixada cuiabana, no período de maio de 2009 a abril de 2010, com o auxílio de um procedimento cálculo de intervalo de confiança não paramétrico por bootstrap. O estudo detectou que a cobertura do céu não contribuiu para a variação do albedo de radiação global durante os períodos estudados, já para a reflexão da radiação PAR e IV, a atmosfera só influenciou numa variabilidade durante o período chuvoso. Quanto a esta mudança proporcionada pela cobertura apenas no período de chuvas, acredita-se que para a reflexão da radiação IV a presença de mais umidade na atmosfera e na superfície foliar tenha contribuído, já para a radiação PAR, acredita-se que a própria mudança na intensidade da mesma em condições de diferentes tipos de cobertura no período chuvoso, possa ter afetado o mecanismo fotossintético da vegetação, alterando assim a reflexão da radiação PAR.
\end{abstract}

Palavras-chave: Radiação refletida, indice de claridade do céu, intervala de confiança.

\begin{abstract}
The energy available for physical, chemical and biological processes on the planet is not entirely consumed by what the sun provides during the day. Part of this energy is returned to the space through reflection, initially by the atmosphere, along with the clouds, and lastly, the surface coverage. This work studied the influence of sky coverage on reflection coefficients of the global radiation. Photosynthetically active (PAR) and infrared (IR) radiation were measured during two periods, dry and rainy, in a region of the Cerrado stricto sensu Cuiabá. These radiation measurement from May 2009 to April 2010 were downloaded and configured with the aid of a calculation procedure for non-parametric confidence interval by bootstrap. The study found that the sky coverage did not contribute to the change in albedo of global radiation during the periods studied, while the reflection of radiation PAR and IV only influenced the atmosphere in variability during the rainy season. As the coverage afforded by this change only occurred during the rainy season, it is believed that the reflection of IR radiation in the presence of higher moisture in the atmosphere and the leaf surface has contributed to the PAR radiation. It is also believed that the change itself is the same intensity under different cover types in the rainy season and may have affected the photosynthetic mechanism of vegetation, thereby altering the reflection of radiation PAR.
\end{abstract}

Keywords: Reflected radiation, clearness index of the sky, confidence interval value.

*cristiano.cunha@cba.ifmt.edu.br

Recebido: 11/10/2013 Revisado: 19/05/2014 Aceito: 15/07/2014 


\section{Introdução}

$\mathrm{O}$ derretimento das calotas polares, as alterações no balanço de radiação da superfície terrestre, as mudanças nos padrões de circulação das correntes marinhas e do vento, e outros problemas ambientais, foram relatados pelo Painel Intergovernamental de $\mathrm{Mu}$ danças Climáticas (Intergovernamental Panel on Climate Change - IPCC 2013) como questões de escala global que, porém, contam com a contribuição de fenômenos que ocorrem em escala local.

O entendimento das mudanças climáticas é um tema de muito interesse da comunidade científica em geral. $\mathrm{O}$ entendimento e mensuração de como se dá o aproveitamento da energia solar pela cobertura vegetal fundamenta estudos de balanço de massa e energia do meio prestante ao desenvolvimento de modelos preditivos para os processos agrícolas, assim como para o estudo de cenários de uso e ocupação do solo.

Esses estudos são de particular importância para Estados com diversos biomas, cada qual com sua riqueza ecológica, variabilidade e seus padrões climáticos, e cuja principal atividade econômica é o agronegócio, em particular o Estado de Mato Grosso. Contudo temos poucos trabalhos científicos de caracterização sazonal do aproveitamento energético, principalmente no que toca a influência da cobertura do céu no albedo da radiação global, e na refletância da radiação fotossinteticamente ativa $(P A R)$ e infravermelha IV.

Com o intuito de contribuir com os estudos ambientais via uma melhor modelagem dos balanços de radiação locais, este trabalho tem como objetivo avaliar a influência da claridade no albedo diário de radiação global, e na refletância da radiação PAR e IV nos períodos seco e chuvoso em uma região de Cerrado mato-grossense.

\section{Material e método}

O local de estudo do presente trabalho é um sítio experimental, situado na divisa da cidade de Cuiabá com o município de Santo Antônio de Leverger. Trata-se de uma propriedade particular conhecida como Fazenda Miranda, estado de Mato Grosso - Brasil, situada a 15

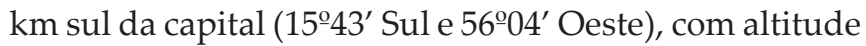
média de $157 \mathrm{~m}$ em uma faixa de transição entre o Cerrado e o Pantanal, com vegetação característica de Cerrado.

O solo desta área é caracterizado por ser pouco espesso, imperfeitamente drenado, concrecionário e com superfície cascalhenta, PLINTOSSOLO PÉTRICO, podendo ocorrer locais com a presença de solos LITÓLICOS DISTRÓFICOS (EMBRAPA,2003).

Neste trabalho, os instrumentos instalados na torre, cujas medidas foram utilizadas para a realização da pesquisa, forram: dois piranômetros modelo LI200X (LI-COR Biosciences, Inc., Lincoln, NE, USA), instalados a $5 \mathrm{~m}$ de altura, um voltado para cima para captar a radiação global incidente e outro voltado para baixo para captar a radiação global refletida. Estes aferem a radiação cujo comprimento de onda está entre 400 a $1100 \mathrm{~nm}$.

Para a aferição da radiação PAR, também foram utilizados dois sensores quantum LI190SB (LI-COR Biosciences, Inc., Lincoln, NE, USA), também instalados a $5 \mathrm{~m}$ de altura, um voltado para cima para captar a radiação PAR incidente e outro voltado para baixo para captar a radiação PAR refletida.

A precipitação pluviométrica (ppt) foi medida por meio de um pluviômetro de báscula modelo TR-525M (Texas Eletronics, Inc., Dallas, TX, USA) instalado a $5 \mathrm{~m}$ de altura do solo.

A planilha de dados coletados pelo datalogger realizou a leitura dos mesmos a uma frequência de $10 \mathrm{~Hz}$, fazendo sua média a cada 30 segundos. Após a realização das médias dos valores encontrados, os mesmos foram armazenados a cada 30 minutos. Para este trabalho, os únicos dados utilizados foram a radiação global incidente e refletida, aferidas em $\mathrm{Wm}^{-2}$. A radiação PAR incidente e refletida foi coletada em $\mu \mathrm{molm}^{-2} \mathrm{seg}^{-1}$. Já a radiação IV foi obtida através da radiação global e PAR. A radiação no topo da atmosfera foi estimada e a precipitação acumulada foi aferida em mm pelo pluviômetro.

As radiações globais incidentes e refletidas já estavam na unidade pretendida para a integração diária da energia. Porém, a radiação PAR não estava em $\mathrm{Wm}^{-2}$. Para a conversão da unidade $\mu \mathrm{molm}^{-2} \mathrm{seg}^{-1}$ para $\mathrm{Wm}^{-2}$, foi utilizada a seguinte relação: $1 \mu \mathrm{mol}=0,2177 \mathrm{~J}$. Para isso, utilizou-se um comprimento de onda médio de 0,55 $\mu \mathrm{m}$, por não se saber o número exato da quantidade de fótons e seus respectivos comprimentos de onda.

A planilha com os dados de radiação global, PAR e IV incidente e refletida, agora já aferidas em $\mathrm{Wm}^{-2}$, foi integrada em cada dia e com seu valor expresso em $\mathrm{MJm}^{-2} \mathrm{dia}^{-1}$. Para isso, após a integração, os valores foram multiplicados por $900 \times 10^{-6}$, que corresponde a conversão dos 30 minutos para segundos e da energia de joule para Mega Joule.

O albedo da Radiação Global mede a parcela da radiação global que é devolvida para a atmosfera. Seu valor varia de acordo com a mudança sofrida pela superfície. Conforme Leitão e Oliveira (2000), o albedo sofre mudanças ao longo dos estádios de crescimento e desenvolvimento das culturas estudadas. Para o cálculo do albedo, utiliza-se a Equação 1.

$$
\alpha_{G}=\frac{R_{g r}}{R_{g i}} \times 100
$$

Nesta equação, $\alpha_{G}$ representa o albedo, que é geralmente expresso em \%. A radiação global refletida aparece no numerador e é indicada por $R_{g r^{\prime}}$ já a radiação global incidente $R_{g i}$ está no denominador. Vale a pena ressaltar que devido à declinação solar o albedo sofre variação também durante o dia, tendo seu valor maior próximo ao início e final do dia e menor entorno do meio dia.

Nas superfícies vegetadas existe uma grande de- 
manda de energia $P A R$, porque é ela a responsável pelo processo anabólico da fotossíntese. Segundo Bani et al. (1995), a otimização desta energia por parte da planta não requer apenas a abundância deste tipo de radiação. Mas de acordo com a literatura, um outro importante fator são valores significativos do IAF.

A grandeza que mede o percentual de radiação $P A R$ devolvida é a refletância deste tipo de energia. Esta grandeza varia dentro dos períodos seco e chuvoso dado a uma mudança que a superfície pode sofrer. Em um trabalho feito por Couto (2009), a reflexão da radiação PAR oscilou de $2 \%$ entre os meses de fevereiro a março para $6 \%$ entre setembro a outubro. Segundo o autor, esse coeficiente aumentou numa escala interanual após um período de três anos de queda contínua da precipitação. Isso mostra a dependência que a grandeza possui da relação entre a precipitação e o crescimento e desenvolvimento da cobertura em questão.

Para o cálculo desta grandeza, basta fazer a razão entre as radiações $P A R$ refletida pela incidente, como se pode visualizar na Equação 2.

$$
\alpha_{P A R}=\frac{P A R_{r}}{P A R_{i}} x 100
$$

Nesta equação, $P A R_{r}$ indica a radiação fotossinteticamente refletida e $P A R_{i}$ a radiação incidente.

O sol emite radiação em praticamente todos os comprimentos de onda. A abrangência do seu espectro vai de 0,15 até $4,0 \mu \mathrm{m}$. Dentro deste intervalo, cerca de 52\% das ondas que chegam a superfície terrestre estão na faixa espectral do infravermelho, cujo comprimento de onda

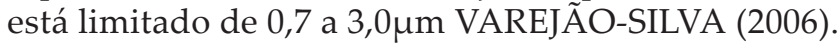

A refletância da radiação infravermelha, quando comparado aos albedos de radiação global e refletância PAR, é o maior de todos. Leitão et al.(2002), em um estudo de albedo em três regiões de floresta, encontrou para estas localidades um maior valor de refletância IV durante todo o dia. Conforme o autor, a variação que esta pode sofrer do período da manhã para o período da tarde, apesar da declinação solar ser a mesma, pode estar relacionada com o grau de umidade na superfície das folhas que diminui no período da tarde em função de uma maior evaporação.

Para o cálculo da reflexão da radiação IV, basta dividir a radiação refletida pela incidente, como mostra a Equação 3, essa metodologia foi usado por Leitão et al. (2002) e também usada por Correia et al. (2002).

$$
\alpha_{I V}=\frac{I V_{r}}{I V_{i}}=\frac{R_{g r}-P A R_{r}}{R_{g i}-P A R_{I}} \times 100
$$

Nesta equação, $I V_{r}$ representa a radiação infravermelha refletida, $I V_{i}$ a incidente e $\alpha_{I V}$ é o albedo IV.

Para a determinação da cobertura do céu, foi utilizado a Equação 4.

$$
K_{T}=\frac{R_{g i}}{R_{o}}
$$

Nessa equação, $R_{g i}$ representa a radiação global incidente na superfície em estudo. $R_{0}$ representa a radiação incidente acima da atmosfera (constante solar). Sendo assim, o valor de $K_{T}$ pode variar de 0 até 1 . Na realização deste estudo, a classificação da cobertura do céu $\left(K_{T}\right)$ será baseada no trabalho de Dalacorte et al. (2004). No intervalo de $0 \leq K_{T}<0,3$ será definido o como céu nublado, entre $0,3 \leq K_{T} \leq 0,65$ como céu parcialmente nublado e entre $0,65<K_{T} \leq 1$ como céu limpo.

O período de estudo contou apenas com 347 dias, os dias que não apareceram no estudo foram momentos em que o equipamento estava recebendo manutenção. $\mathrm{Na}$ maior parte dos dias do período estudado, as coberturas do céu foram Parcialmente Nublados, porém, foram observados os três tipos de cobertura. No entanto, o Período Seco teve um maior percentual de dias nublados, $14 \%$. Em compensação, o período chuvoso teve menos dias claros, 3\%.

A radiação global incidente no topo da atmosfera foi estimada pela mesma equação usada por OMETTO (1981). Nesta foi considerado a latitude $(\varphi)$ do local, valor em graus correspondente a 15,7315. Determinou-se também a declinação solar ( $\delta$ ) com a Equação 5, o valor do ângulo horário do nascer do sol (hn) com a Equação 6, o valor quadrado da distância média entre a Terra e o Sol pela distância real em determinado Dia Juliano $\left(\frac{d}{D}\right)^{2}$ foi obtido com a Equação 7. Após estes cálculos, o valor estimado da radiação solar $\left(Q_{0}\right)$ no topo atmosférico ao longo dos dias foi obtido, já em $\mathrm{MJdia}^{-1} \mathrm{~m}^{-2}$.

$$
\begin{aligned}
& \delta=23,45 \cdot \operatorname{sen}\left[\frac{360}{364}(284+D J)\right] \\
& h n=\arccos [-\tan \phi \cdot \tan \delta]+0,83 \\
& \left(\frac{d}{D}\right)^{2}=1+0,033 \cdot \cos \left(\frac{D J \cdot 360}{365}\right)
\end{aligned}
$$

Após a separação e classificação das coberturas dos dias dentro de cada período, foi calculado o albedo da radiação global, a refletância IV e $P A R$ para os dias nublados, parcialmente nublados e claros do período seco e depois do período chuvoso.

Para a análise estatística dos dados, foi utilizado o método de bootstrap. Tal método foi criado por Bradley Efron (1979). Essa técnica utiliza da amostra, computando suas médias por diversas vezes, em que combina a retirada de alguns dados e a repetição de outros dados. Para Cesário e Barreto (2003), quando se pretende construir um intervalo de confiança, a utilização do método bootstrap é uma alternativa computacionalmente intensiva 


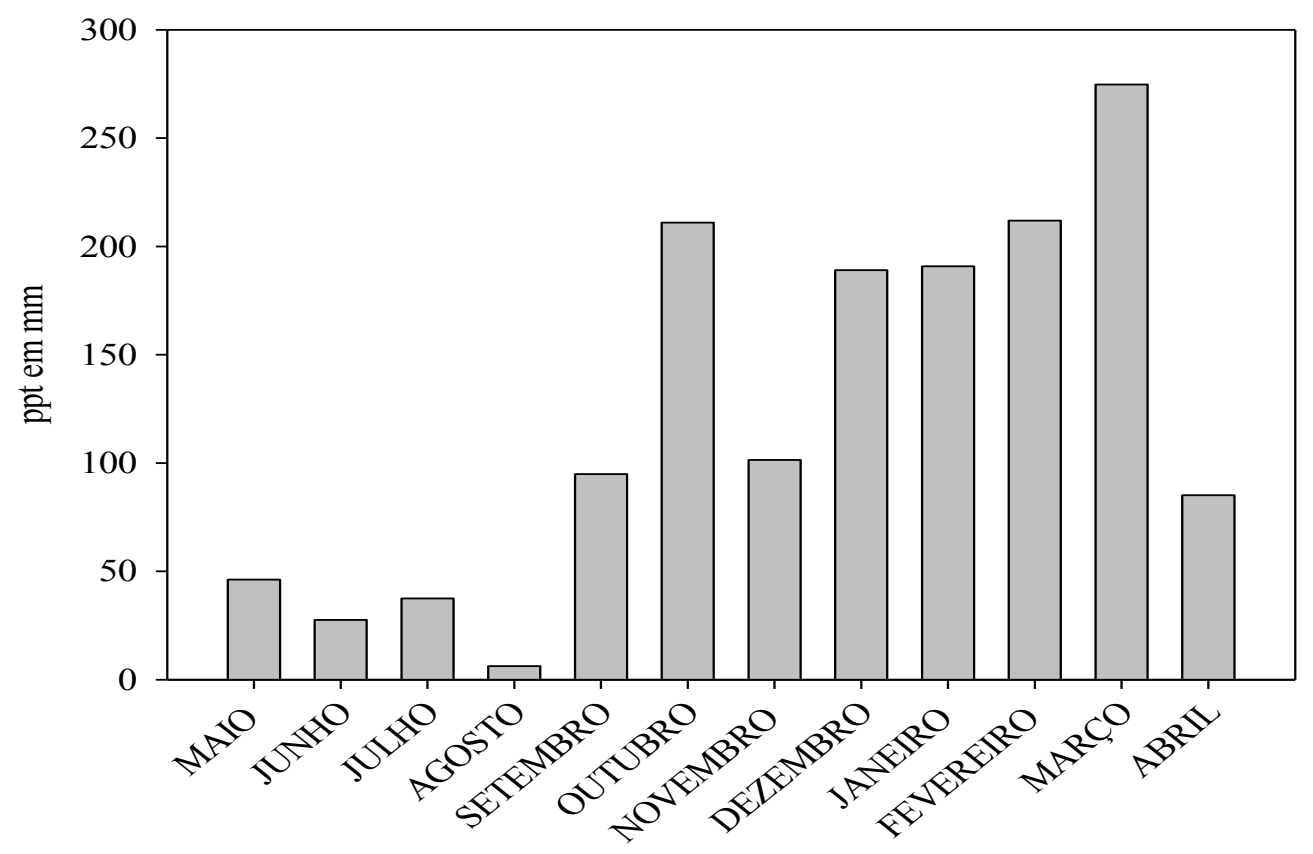

Figura 1. Distribuição do regime de precipitação acumulada no Período Seco (maio a outubro de 2009) e Período Chuvoso (novembro de 2009 a abril de 2010).

e eficiente. Como nesse estudo existem amostras bem pequenas, as diversas vezes que o método realiza para a geração dos intervalos torna o mesmo bem seguro, dado o elevado número de combinações que esse realiza.

O procedimento consiste na simulação de uma função densidade de probabilidade a partir do cálculo recursivo das estatísticas em estudo a partir de reamostragem. Estas, por sua vez, são obtidas com reposição a partir da amostra original (bootstrap não paramétrico) ou de um modelo de distribuição a priori, usualmente a Normal, com parâmetros estimados via amostra original (bootstrap paramétrico).

Posto que verificamos pelo teste de Kolmogorov-Smirnov que o albedo não adere a distribuição Normal, utilizamos o bootstrap não-paramétrico, estimando os intervalos de confiança pelos percentis (2,5\% e 97,5\%) da distribuição simulada. Neste trabalho foram estimados os intervalos de confiança para cada albedo e refletância calculados, dentro de cada período, considerando as três condições de cobertura do céu. O método bootstrap foi aplicado com o suporte do softwear Oracle Crystal Ball com 1000 reamostragem.

\section{Resultados e discussão}

A pesquisa realizada nesta região levou em conta dois períodos sazonais. Período seco de 2009, compreendido entre os meses de maio a outubro, e período chuvoso, compreendido entre os meses de novembro a abril de 2010. Trabalhos realizados por Antunes Junior (2010) e por Rodrigues (2011), na mesma região, mostraram que as variáveis meteorológicas possuem um comportamento bem distinto nestes períodos. Dessa forma, a sazonalidade foi divida conforme o regime de precipitação, Figura 1.

O Período Seco apresentou uma precipitação cuja média foi de $71 \mathrm{~mm} / \mathrm{mês}$, já o período chuvoso teve uma média de $176 \mathrm{~mm} / \mathrm{mês}$. O trabalho teve início com a integração da radiação global incidente e com a estimativa da radiação no topo da atmosfera. Com a obtenção do índice $K t$, a cobertura do céu foi encontrada para os períodos seco e chuvoso, conforme a Tabela 1.

Após os cálculos via bootstrap, os intervalos de confiança, foram gerados os gráficos de cada período levando em conta o tipo de cobertura. Observando os valores obtidos para o período seco, notamos que estes são em média, maiores que aqueles obtidos no período chuvoso. No trabalho de Moraes et al. (2012), os autores mostram que tal característica se deve a sazonalidade desta variável frente as mudanças sofridas pela superfície quando do início e fim do período chuvoso

Através da análise dos gráficos na Figura 2, percebese que a cobertura do céu não influenciou a variação do albedo global para o período seco e nem para o período chuvoso, visto que os intervalos de confiança para as três coberturas possuem seus limites ora superior ora inferior coincidindo com o intervalo de confiança da outra cobertura. Dessa forma, na região onde feita esta pesquisa, a variação da intensidade da radiação da radiação global não altera o padrão de reflexão desta radiação.

Na Figura 3 foi feito a mesma observação para a radiação $P A R$, vale apena relembrar que a análise está consistindo na observação ou não de uma coincidência de um dos limites do intervalo de confiança dentro dos 
Tabela 1. Determinação do total de dias e suas coberturas.

\begin{tabular}{ccc}
\hline Classificação do dia & $\begin{array}{c}\text { Período Seco } \\
\text { (Total de 184 dias) }\end{array}$ & $\begin{array}{c}\text { Período Chuvoso } \\
\text { (Total de 163 dias) }\end{array}$ \\
\hline $\begin{array}{c}\text { Dias Claros } \\
\left(K_{t}<0,3\right)\end{array}$ & 25 & 4 \\
Dias $P$. Nublados & 134 & 139 \\
$\left(0,3 \leq K_{t} \leq 0,65\right)$ & & 20 \\
Dias Nublados & 25 & \\
$\left(K_{t}>0,65\right)$ & &
\end{tabular}

períodos.

Para o período seco, a variação da intensidade da radiação $P A R$ não afetou a reflexão desta radiação, isso por que os limites inferiores dos dias claros e parcialmente nublados estão dentro do intervalo de confiança dos dias nublados. Já no período chuvoso, houve influência, visto que o limite superior dos dias claros está abaixo do limite inferior dos dias parcialmente nublados, já os dias parcialmente nublados possuem um limite superior menor que o limite inferior dos dias nublados.

Alguns trabalhos, como (ARAÚJO \& DEMINICIS, 2009., DIAS \& MARENCO, 2007., FILHO , 2000., MARENCO et al., 2007) relatam que o aumento excessivo da luz acima da capacidade de utilização pela fotossíntese pode resultar em uma condição de estresse conhecida como fotoinibição, esse excesso não diz respeito apenas a radiação $P A R$, mas também da radiação global.

Em um estudo realizado por Mota et al. (2009) feito com videiras, duas plantações foram comparadas, uma possuía cobertura artificial de tela cujo objetivo era minimizar a intensidade da radiacão incidente, a outra plantação estava descoberta e exposta a toda radiação proveniente do Sol. Os pesquisadores concluíram neste experimento que a cobertura reduziu em $30 \%$ a disponibilidade de radiação $P A R$ e favoreceu a abertura estomática e o potencial fotossintético foliar.

No trabalho de Rodrigues (2011) nesta mesma localidade da presente pesquisa, foi verificada uma sozanalidade da radiação solar, umidade no solo, umidade relativa e temperatura média do ar. A sazonalidade destas variáveis micrometeorológica pode afetar o comportamento da vegetação local.

Nesta região, a média da radiação $P A R$ no período seco foi de 4,2582 W.m-2 , com máxima de 6,5840 e mínimo de 0,7702 . A radiação global neste período teve média de 16,443 W.m² ${ }^{-2}$ com máximo de 26,128 e mínima de 2,611 , já no período chuvoso a média da radiação $P A R$ foi de 4,463 W.m-2 com máximo de 8,2829 e mínimo de 0,873 . A radiação global teve média de $17,53 \mathrm{~W} \cdot \mathrm{m}^{-2} \mathrm{com}$ máxima de 26,417 e mínima de 3,041.

Diante de uma série de trabalhos terem mostrado aue o comportamento fotossintético das vegetações

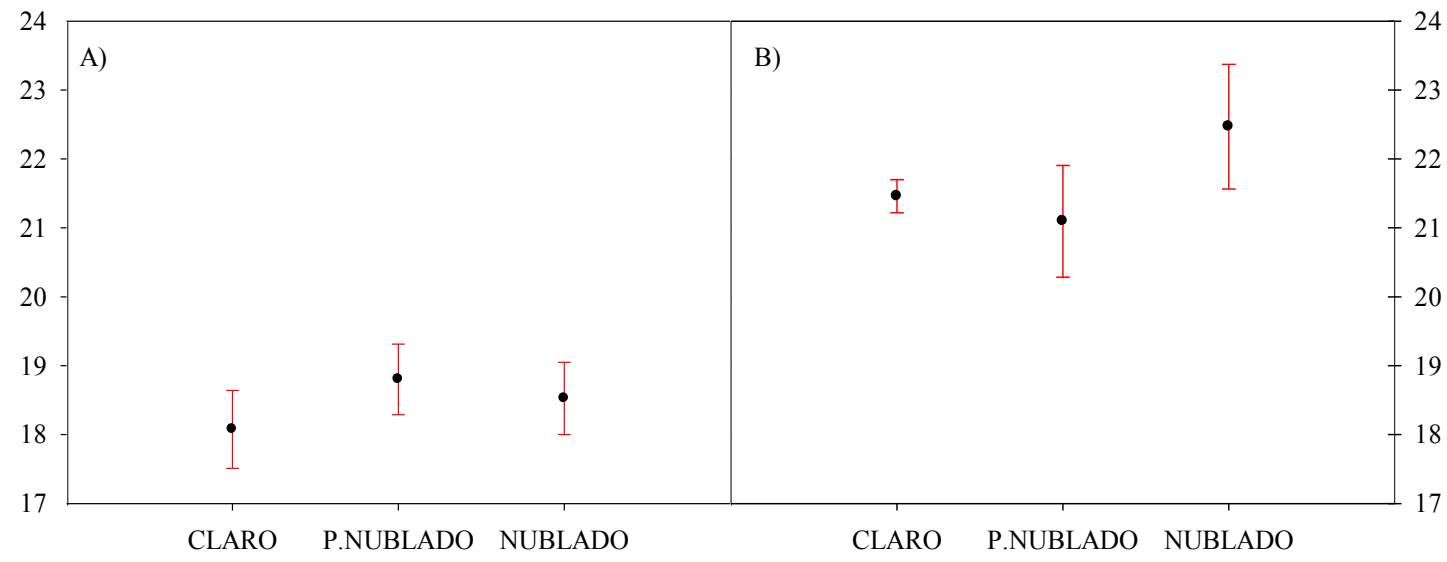

Figura 2. No gráfico " $\mathrm{A}$ " temos o intervalo de confiança para o albedo global em percentual no período seco, já no gráfico " $\mathrm{B}$ " intervalo de confiança para o albedo global em percentual no período chuvoso. 


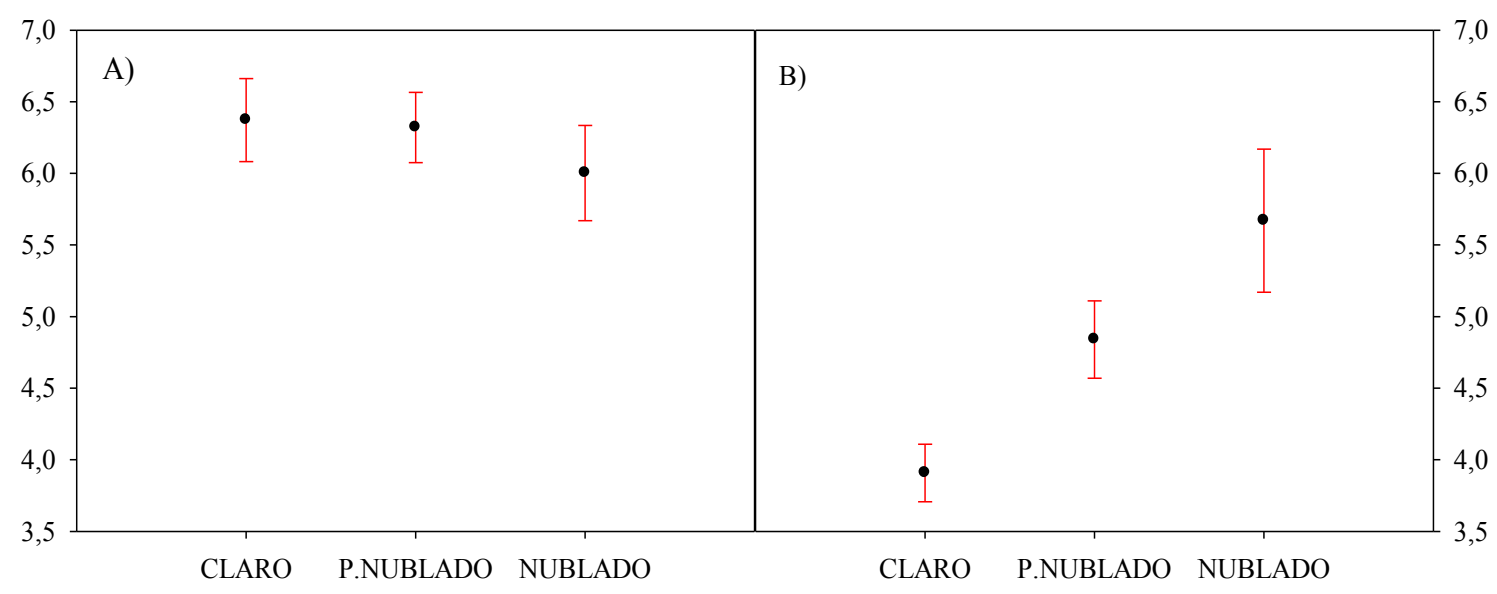

Figura 3. No gráfico "A" temos o intervalo de confiança para a refletância da radiação PAR em percentual no período seco, já no gráfico "B" intervalo de confiança do período chuvoso.

sofrem alterações devido a variações na intensidade da radiação incidente sobre a vegetação, isso faz acreditar que a mudança sofrida pela refletância da radiação $P A R$ no período chuvoso, pode ser uma indicação da resposta da cobertura frente à mudança da intensidade desta radiação.

Este trabalho mostra que a alteração da intensidade da radiação incidente pode ter causado mudança no potencial fotossintético, reforçando assim a possibilidade disto ter influenciado nas variações da refletância da radiação $P A R$.

No período seco, o intervalo de confiança para as diferentes coberturas apresenta coincidência de seus limites dentro dos outros intervalos, isso demonstrou uma não dependência da cobertura com a refletância da radiação IV. Já no período chuvoso, como se observa no gráfico " $\mathrm{B}$ ", percebe-se que não há simultaneidade nos intervalos dos momentos de céu claro com os dias parcialmente nublados, sendo que o limite inferior dos dias de céu claro é maior que o limite superior dos dias parcialmente nublados.

Em um estudo feito por Leitão et al.(2002), acredita-se que a variação deste índice pode estar associado à diferença de umidade retida pelo vegetal e também à presença de água na superfície foliar, então, como a presença de cobertura no céu durante o período chuvoso pode indicar que houve precipitação no local ou próximo dele naqueles dias, por isso, o ar tem sua umidade relativa aumentada ou a própria superfície foliar possui lâminas d'água, talvez essa pode ter sido a causa desta variação na refletância IV durante o período chuvoso.

$\mathrm{O}$ período seco, como indicou o gráfico " $\mathrm{A}$ ", não apresentou variação neste índice, como no estado de Mato Grosso existem muitas queimadas durante o período seco, e o ano de 2010 foi um dos mais críticos neste índice (Inpe (NOAA 15) - Análise ICV), é provável

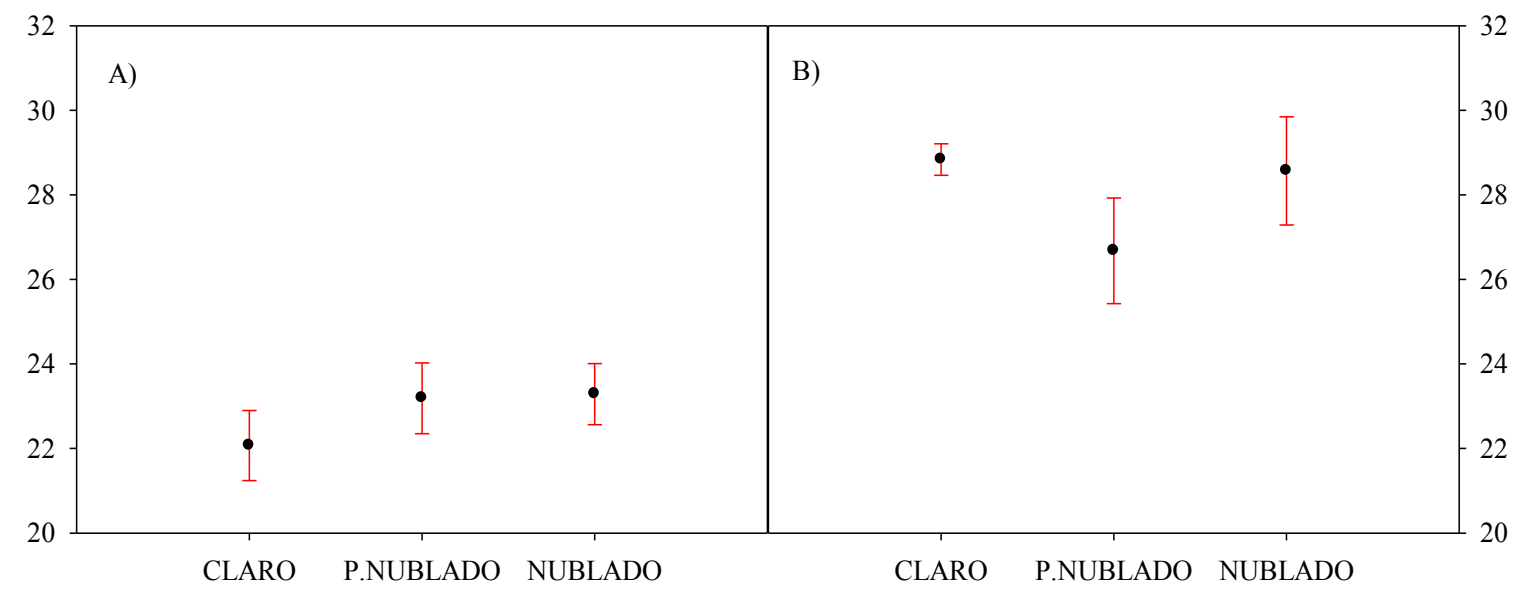

Figura 4. No gráfico "A" temos o intervalo de confiança para a refletância da radiação IV em percentual no período seco, já no gráfico "B" intervalo de confiança do período chuvoso. 
que a cobertura que exista no céu neste momento seja proveniente da existência de fuligem e poeira ALMEIDA FILHO (2011). Como esta cobertura não é certeza de precipitação para o período seco, não há variação na umidade retida pela vegetação ou sobre sua superfície, justificando assim sua permanência constante ao logo de diferentes coberturas do céu para o período seco.

\section{Conclusão}

O estudo mostrou a existência dos três tipos de coberturas do céu nos períodos seco e chuvoso, com um maior percentual de dias parcialmente nublado. Após a plotagem gráfica dos albedos diários, considerando cada tipo de cobertura dentro dos períodos estudados, foi percebida uma oscilação dos valores, porém, após a análise estatística pelo método de bootstrap, chegou-se a conclusão que a cobertura do céu só influenciou as refletâncias das radiações $P A R$ e IV no período chuvoso, já o albedo de radiação global não sofreu influência da cobertura em nenhum dos períodos.

\section{Referências}

ALMEIDA FILHO, E. O. Variabilidade Sazonal e Temporal das Propriedades Ópticas de Aerossóis Atmosféricos na Amazônia. Cuiabá, 2011. 120p. Tese (Doutorado) - Física Ambiental, Universidade Federal de Mato Grosso.

ANTUNES JÚNIOR, M. Z. Influência de variáveis microclimáticas no balanço de energia e intercâmbio gasoso em área de Pastagem no cerrado mato-grossense. 101p. Dissertação (Mestrado em Agricultura Tropical) - Faculdade de Agronomia e Medicina Veterinária, Universidade Federal do Mato Grosso, Cuiabá, 2010.

ARAÚJO, S.A.C., DEMINICIS, B.B., Fotoinibição da Fotossíntese. Revista Brasileira de Biociências, Porto Alegre, v.7, n.4, p. 463-472, out./dez. 2009.

BANI, N.A., BERLATO, M.A., BERGAMASCHI, H., RIBOLDI, J., Rendimento Máximo de Girassol com base na Radiação Solar e temperatura: II. Produção de fitomassa e rendimento de grãos. PESQ.

AGROP. GAÚCHA, Porto Alegre, v.1,n.2,p. 2012216, 1995.

CESÁRIO, L.C., BARRETO, M.C.M., Um estudo sobre o desempenho de intervalos de confiança bootstrap para a média de uma distribuição normal usando uma amostragem por conjuntos ordenados perfeitamente. Ver. Mat. Est., São Paulo, v.21, p-7-
$20,2003$.

CORREIA, F.W.S., ALVALÁ, R.C.S., GIELOW, R., Albedo do Pantanal Sul Matogrossense durante o período de transição seco-úmido de 2001-2002. XII Congresso Brasileiro de Meteorologia, Foz do Iguaçu - PR, 2002.

COUTO, Diogo Ladvocat Negrão. Albedo em cerrado sensu stricto como resposta à variação climática e biológica: conexões com índice de vegetação, estoques de carbono e fluxos de CO2. 2009. Dissertação (Mestrado em Geografia Física) Faculdade de Filosofia, Letras e Ciências Humanas, Universidade de São Paulo, São Paulo, 2009.

Disponível em: <http://www.teses.usp.br/teses/ disponiveis/8/8135/tde-04022010-133248/>. Acesso em: 2012-04-12.

DALLACORT, R., RICIERI, R. P., SILVA, S. L., FREITAS, P. S. L., SILVA, F. F.

FILHO-LEMOS, J.P., Fotoinibição em três espécies do cerrado (Annona crassifólia, Eugenia dysenterica e Campomanesia adamantium) na estação seca e chuvosa. Revista Brasileira de Fruticultura, Boticabal - SP, v.23, n.1, p.45-50, mar. 2000.

DIAS, D.P., MARENCO, R.A., Fotossíntese e fotoinibição em mogno e acariquara em função da luminosidade e temperatura foliar. Pesquisa Agropecuária Brasileira, v.42, n.3, p.305 - 311, mar. 2007.

FILHO-LEMOS, J.P., Fotoinibição em três espécies do cerrado (Annona crassifólia, Eugenia dysenterica e Campomanesia adamantium) na estação seca e chuvosa. Revista Brasileira de Fruticultura, Boticabal - SP, v.23, n.1, p.45-50, mar. 2000.

LEITÃO, M.M.V.B.R; MOURA, M.S.B; SALDANHA, T.R.F.C; SOBRINHO, J.E; OLIVEIRA, G.M. Balanço de Radiação Sobre um Solo Descoberto para quatro Períodos do Ano. Revista de Ciência \& Tecnologia . 15 - PP. 59-66, Junho 2000.

LEITÃO, M.V.B.R., SANTOS, J.M., OLIVEIRA, G.M., Estimativas do albedo em três ecossistemas da floresta amazônica. Revista Brasileira de Engenharia Agrícola e Ambiental, v.6, n.1, p.256261,2002. Campina Grande, PB, DEAg/UFCG.

LEITÃO, M.M.V., OLIVEIRA, G.M., Influência da Irrigação sobre o Albedo. Revista Brasileira de Engenharia Agrícola e Ambiental, v.4, n.2, p.214218,2000 Campina Grande, PB, DEAg/UFPD. 
MARENCO, R.A., NEVES, T.S., CAMARGO, M.A.B., DIAS, D.P,. COSTA, G.F.C., RODRIGUES, J.C., Fotoinibição dinâmica da fotossíntese em árvores de dossel da Amazônia Central. Revista Brasileira de Biociências, Porto Alegre, v.5, supl.2, p. 150-152, jul. 2007.

MORAES, M.G.S., FINGER, A., PAULO, I.J.C., Caracterização preliminar da variabilidade do albedo da superfície no cerrado sensu stricto matogrossense. Revista Brasileira de Ciências Ambientais, São Paulo, n. 26, dezembro de 2012.

MOTA, C.S., AMARANTE, C.V.T., SANTOS, H.P., ALBUQUERQUE, J.A., Disponibilidade hídrica, radiação solar e fotossíntese em videiras 'cabernet sauvigno' sob cultivo protegido. Revista Brasileira de Fruticultura, Jaboticabal - SP, v.31, n.2, p. 432 439, Junho 2009.

OMETTO, J.S. Bioclimatologia vegetal. São Paulo: Agronômica Ceres, 1981. 425p.

RODRIGUES, T.R., Variabilidade Interanual da Sazonalidade de Fluxos de Energia e Matéria em Área de Cerrado na Baixada Cuiabana. 86p. Dissertação (Mestrado em Física Ambiental) Instituo de Física - Universidade Federal de Mato Grosso, Cuiabá - 2011.

VAREJÃO-SILVA, M.A. Meteorologia e Climatologia. Versão digital, Recife, 2006. 522p. 